\title{
The Effects of Clamp and Shunt Usage on Vascular Endothelium in Coronary Artery Bypass Grafting Surgery
}

\author{
Habib Cakir $^{1 *}$, Ismail Yüreklii ${ }^{1}$, Koksal Donmez ${ }^{1}$, Yuksel Besir ${ }^{1}$, Mert Kestelli $^{1}$, Ersin Celik ${ }^{1}$, \\ Banu Bahriye Akdag Lafci ${ }^{1}$, Ufuk Yetkin ${ }^{1}$, Ali Gürbüz ${ }^{2}$ \\ ${ }^{1}$ Department of Cardiovascular Surgery, Izmir Atatürk Education and Research Hospital, Izmir, Turkey \\ ${ }^{2}$ Cardiovascular Surgery, Katip Celebi Universitesi Ataturk Education and Training Hospital, Izmir, Turkey \\ Email: "habibcakir35@hotmail.com
}

Received September 14, 2013; revised November 14, 2013; accepted November 21, 2013

Copyright (C) 2013 Habib Cakir et al. This is an open access article distributed under the Creative Commons Attribution License, which permits unrestricted use, distribution, and reproduction in any medium, provided the original work is properly cited.

\begin{abstract}
In this review we aimed to present the effects of clamp and shunt usage on vascular endothelium in coronary artery surgery under the light of current literature data. Each surgical team or even each surgeon uses different methods in order to create bloodless surgical site during beating heart surgical procedures. Every method has its own advantages and disadvantages. There is no formed consensus regarding this issue. Surgeons still want to operate on bloodless surgical fields. But, they have concerns about continuity of blood flow and vascular endothelial injury during off-pump coronary surgery. In order to achieve a consensus statement about this issue, multicentric larger studies are needed.
\end{abstract}

Keywords: Coronary Artery Bypass Surgery; Shunt; Endothelial Injury; Clamp

\section{Introduction}

Coronary artery bypass grafting surgery is a safe and reliable method for coronary artery disease. Coronary artery bypass grafting may be performed as off-pump (beating heart) or on-pump surgery. Surgeon's experience and coronary arteries' anatomic positions are two major factors affecting this choice. Coronary artery clamping or intracoronary shunt usage is commonly used for obtaining bloodless surgical site during beating heart surgical procedures. Occlusion of coronary artery during beating heart surgical procedures may potentially cause endothelial damage [1]. Some of the surgeons prefer clamping while others prefer routine intracoronary shunt usage. There is no consensus among surgeons in terms of preference of these two methods.

In this review we aimed to present the effects of clamp and shunt usage on vascular endothelium in coronary artery surgery under the light of current literature data.

\section{Clamp and Shunt Usage at Coronary Artery Bypass Grafting Surgery}

Coronary artery bypass grafting surgery is a very effective method in treatment of coronary artery disease. Due

"Corresponding author. to technological advances and increased surgical experience, beating heart coronary artery bypass grafting surgery is being more commonly preferred. Continuity of coronary blood flow while performing distal anastomosis is one of the major issues in beating heart coronary artery bypass grafting surgery. Nevertheless, bloodless surgical site is very important for performing a good anastomosis. Surgeons may choose clamping or intracoronary shunt usage according to their own preference or coronary artery anatomy. Clamping creates ischemia at target coronary arterial territory and late term stenosis may occur because of endothelial damage [2]. Also local thrombosis and atherosclerotic plaque rupture may occur [3]. Rivetti et al. have shown that intraluminal shunt usage reduced coronary ischemia [2]. In contrast Hangler et al. reported that intracoronary shunt usage caused distal endothelial damage at coronary arteries and they recommended this technique to be used only at selected cases with critical ischemia [4]. Occlusions performed during beating heart coronary artery bypass grafting surgery cause endothelial damage [1]. Hangler et al. reported the importance of intracoronary shunt usage in patients with critical ischemia [1]. Bozok et al. reported that postoperative troponin I levels were lower and myocardial edema was less in beating heart coronary artery bypass grafting surgery 
patients in those intracoronary shunt was preferred [5]. Similarly, Menon et al. reported that intracoronary shunt usage reduced coronary artery ischemia and wall motion abnormalities. Also they reported that early graft patencies were better [6]. Gandra et al. reported that according to their clinical observations intracoronary shunt usage caused less myocardial ischemia [7]. Safei et al. compared beating heart coronary artery bypass grafting surgery patients with and without intracoronary shunting and found out that patients with shunt usage had less cardiac enzyme change. There were no statistical significant difference between two groups regarding the electrocardiographic changes, myocardial infarction, left ventricular ejection fraction, mortality and morbidity [8]. Similarly, Gurbuz et al. found higher Troponin I levels in patients without intracoronary shunting [9]. They also report that anastomosis takes much longer time with intracoronary shunt usage. Bozok et al. reported longer anastomosis time with intracoronary shunt usage [5]. Also endothelial damage related to intracoronary shunt usage is reported [10]. There may be such problems as impossible positioning of intracoronary shunt [11].

There are reports of coronary clamps applied for creating bloodless operation site at beating heart coronary artery bypass grafting surgery causing lesser endothelial damage [12]. Perrault et al. suggested that clamp or intracoronary shunt usage at atherosclerotic coronary arteries does not cause additional endothelial damage. They have not discussed platelet aggregation, intimal dissection and plaque rupture in their report [13].

\section{Result}

Each surgical team or even each surgeon uses different methods in order to create bloodless surgical site during beating heart surgical procedures. Every method has its own advantages and disadvantages. There is no formed consensus regarding this issue. While surgeons still want to operate on bloodless surgical fields, they have concerns about continuity of blood flow and vascular endothelial injury. In order to achieve a consensus statement about this issue, multicentric larger studies are needed.

\section{REFERENCES}

[1] H. Hangler, L. Mueller, E. Ruttmann, H. Antretter, K. Pfaller, "Shunt or Snare: Coronary Endothelial Damage Due to Hemostatic Devices for Beating Heart Coronary Surgery," The Annals of Thoracic Surgery, Vol. 86, No. 6, 2008, pp. 1873-1877. http://dx.doi.org/10.1016/j.athoracsur.2008.06.047

[2] L. A. Rivetti and S. M. Gandra, "An Intraluminal Shunt for Off-Pump Coronary Artery Bypass Grafting. Report of 501 Consecutive Cases and Review of the Technique," Heart Surgery Forum, Vol. 1, No. 1, 1998, pp. 30-36.
[3] H. B. Hangler, K. Pfaller, H. Antretter, O. E. Dapunt and J. O. Bonatti, "Coronary Endothelial Injury after Local Occlusion on the Human Beating Heart," The Annals of Thoracic Surgery, Vol. 71, No. 1, 2001, pp. 122-127. http://dx.doi.org/10.1016/S0003-4975(00)02181-0

[4] H. B. Hangler, K. Pfaller, E. Ruttmann, D. Hoefer, T. Schachner, G. Laufer, et al., "Effects of Intracoronary Shunts on Coronary Endothelial Coating in the Human Beating Heart," The Annals of Thoracic Surgery, Vol. 77, No. 3, 2004, pp. 776-780. http://dx.doi.org/10.1016/j.athoracsur.2003.08.052

[5] S. Bozok, G. İlhan, H. Karamustafa, S. Ozan Karakişi, N. Tüfekçi, Y. Tomak, et al., "Influence of Intracoronary Shunt on Myocardial Ischemic Injury during Off-Pump Coronary Artery Bypass Surgery," The Journal of Cardiovascular Surgery, Vol. 54, No. 2, 2013, pp. 289-295.

[6] A. K. Menon, J. M. Albes, M. Oberhoff, K. R. Karsch and G. Ziemer, "Occlusion Versus Shunting During MIDCAB: Effects on Left Ventricular Function and Quality of Anastomosis," The Annals of Thoracic Surgery, Vol. 73, No. 5, 2002, pp. 1418-1423. http://dx.doi.org/10.1016/S0003-4975(02)03472-0

[7] S. M. Gandra and L. A. Rivetti, "Experimental Evidence of Regional Myocardial Ischemia during Beating Heart Coronary Bypass: Prevention with Temporary Intraluminal Shunts," Heart Surgery Forum, Vol. 6, No. 1, 2002, pp. 10-18.

[8] N. Safaei, H. M. Gaem and H. Alikhah, "Intracoronary Shunt in Off-Pump Coronary Artery Bypass Graft," Pakistan Journal of Biological Sciences, Vol. 13, No. 1, 2010, pp. 40-45. http://dx.doi.org/10.3923/pjbs.2010.40.45

[9] A. Gürbüz, B. Emrecan, L. Yilik, I. Ozsöyler, M. Kestelli, C. Ozbek, et al., "Intracoronary Shunt Reduces Postoperative Troponin Leaks: A Prospective Randomized Study," European Journal Cardio-Thoracic Surgery, Vol. 29, No. 2, 2006, pp. 186-189.

http://dx.doi.org/10.1016/j.ejcts.2005.11.014

[10] S. P. Collison, A. Agarwal and N. Trehan, "Controversies in the Use of Intraluminal Shunts During Off-Pump Coronary Artery Bypass Grafting Surgery," The Annals of Thoracic Surgery, Vol. 82, No. 4, 2006, pp. 1559-1566. http://dx.doi.org/10.1016/j.athoracsur.2006.05.019

[11] R. G. Demaria, S. Fortier, O. Malo, M. Carrier and L. P. Perrault, "Influence of Intracoronary Shunt Size on Coronary Endothelial Function During Off-Pump Coronary artery Bypass," Heart Surgery Forum, Vol. 6, No. 3, 2003, pp. 160-168.

[12] C. Hsi, H. Cuenoud, B. R. Soller, H. Kim, J. Favreau, T. J. Vander Salm, et al., "Experimental Coronary Artery Occlusion: Relevance to Off-Pump Cardiac Surgery," Asian Cardiovascular and Thoracic Annals, Vol. 10, No. 4, 2002, pp. 293-297.

http://dx.doi.org/10.1177/021849230201000402

[13] L. P. Perrault, C. Nickner, N. Desjardins and M. Carrier, "Effects on Coronary Endothelial Function of the Cohn Stabilizer for Beating Heart Bypass Operations," The Annals of Thoracic Surgery, Vol. 70, No. 3, 2000, pp. 1111-1114. http://dx.doi.org/10.1016/S0003-4975(00)01789-6 